\title{
Comparison between Satellite Water Vapour Observations and Atmospheric Models' Predictions of the Upper Tropospheric Thermal Radiation
}

\author{
J. R. Dim,, T. Y. Nakajima, ${ }^{1}$ T. Takamura, ${ }^{3}$ and N. Kikuchi ${ }^{4}$ \\ ${ }^{1}$ Earth Observation Research Center, Japan Aerospace Exploration Agency, 2-1-1 Sengen, Tsukuba, Ibaraki 305-8505, Japan \\ ${ }^{2}$ Department of Network and Computer Engineering, School of Information \& Design Engineering, Tokai University, 2-28-4, \\ Tomigaya, Shibuya-ku, Tokyo 151-0063, Japan \\ ${ }^{3}$ Center for Environmental Remote Sensing, Chiba University, 1-33 Yayoi-cho, Inage-ku, Chiba 263-8522, Japan \\ ${ }^{4}$ Center for Global Environmental Research, National Institute for Environmental Studies, 16-2 Onogawa, Tsukuba, \\ Ibaraki 305-8506, Japan
}

Correspondence should be addressed to J. R. Dim, dimjules.rostand@jaxa.jp

Received 14 October 2011; Accepted 12 December 2011

Academic Editor: Klaus Dethloff

Copyright ( $) 2011$ J. R. Dim et al. This is an open access article distributed under the Creative Commons Attribution License, which permits unrestricted use, distribution, and reproduction in any medium, provided the original work is properly cited.

\begin{abstract}
Atmospheric profiles (temperature, pressure, and humidity) are commonly used parameters for aerosols and cloud properties retrievals. In preparation of the launch of the Global Change Observation Mission-Climate/Second-Generation GLobal Imager (GCOM-C/SGLI) satellite, an evaluation study on the sensitivity of atmospheric models to variations of atmospheric conditions is conducted. In this evaluation, clear sky and above low clouds water vapour radiances of the upper troposphere obtained from satellite observations and those simulated by atmospheric models are compared. The models studied are the Nonhydrostatic ICosahedral Atmospheric Model (NICAM) and the National Center for Environmental Protection/Department Of Energy (NCEP/DOE). The satellite observations are from the Terra/Moderate Resolution Imaging Spectroradiometer (Terra/MODIS) satellite. The simulations performed are obtained through a forward radiative transfer calculation procedure. The resulting radiances are transformed into the upper tropospheric brightness temperature (UTBT) and relative humidity (UTRH). The discrepancies between the simulated data and the observations are analyzed. These analyses show that both the NICAM and the NCEP/DOE simulated UTBT and UTRH have comparable distribution patterns. However the simulations' differences with the observations are generally lower with the NCEP/DOE than with the NICAM. The NCEP/DOE model outputs very often overestimate the UTBT and therefore present a drier upper troposphere. The impact of the lower troposphere instability (dry convection) on the upper tropospheric moisture and the consequences on the models' results are evaluated through a thunderstorm and moisture predictor (the K-stability index). The results obtained show a positive relation between the instability and the root mean square error (RMSE: observation versus models). The study of the impact of convective clouds shows that the area covered by these clouds increases with the humidity of the upper troposphere in clear sky and above low clouds, and at the same time, the error between the observations and the models also increases. The impact of the above low clouds heat distribution on the models is studied through the relation between the low clouds cover and their effective emissivity. The models' error appears to be high at midrange effective emissivity clouds.
\end{abstract}

\section{Introduction}

For a reliable computation of the Earth radiation budget, the accuracy of the upper tropospheric relative humidity (UTRH) is essential. The UTRH is a widely varying parameter in the water vapour feedback of the climate as well as a major regulating factor of radiation exchanges between the ground surface and the sun. Reducing current uncertainties involving water vapour in the climate system requires accurate global measurement modeling and long-term prediction of water vapour [1]. Water vapour in the upper troposphere, while insignificant by total mass of column water vapour, can have significant effects on climate, through the formation of clouds (longwave cloud forcing) or by direct absorption of 
radiation [2]. The distribution of water vapour in the upper troposphere is generally influenced by two major processes: the atmospheric convection and subsidence. The relation between these processes and the UTRH may be positive or negative depending on cloud movements, position, optical and physical properties, and the general atmospheric circulation. Details of the rapid changes of water vapour quantities in the upper troposphere can only be obtained if frequent and high-resolution satellite observations are available; these satellite data should be integrated into atmospheric models to understand future climate changes and water vapour processes [1]. Various aspects of these processes in the upper troposphere can be examined with large or mesoscale atmospheric models. This explains the usage of these models' outputs (as ancillary data) for clouds and aerosols properties retrievals. The quality of clouds and aerosols retrievals depends among other factors on the accuracy of these models and their ability to properly depict atmospheric phenomena. The future launch of the GCOM-C/SGLI satellite (successor of the ADEOS/GLI) is the incentive for the present study. The atmospheric models examined could serve as supporting data for clouds, aerosols, and water vapour retrievals from this satellite's observation. The models discussed in this study are the NICAM and NCEP/DOE models. The NICAM belongs to the category of mesoscale atmospheric models. These kinds of models, designed for numerical weather predictions, have proven useful for diagnostic studies of the coupling between atmosphere dynamics and physical processes [3]. And they generally involve a cloud-resolving scheme generated by various techniques (e.g., icosahedral grid techniques) and a global cloud simulation [4]. Unlike general circulation models, cloud-resolving models cover a small domain but have fine horizontal and vertical resolutions that resolve convection and clouds [4]. The second model examined in this study is the NCEP/DOE model. It is a general circulation model producing atmospheric analyses (reanalysis-2 data) based on past and current observations.

In the present study, the performance of the predictions of the NICAM and NCEP/DOE models is examined through a comparison of the models' simulated atmospheric parameters (UTBT and UTRH) with observations from the Terra/MODIS satellite. Simulated emissions of outgoing radiances in the $6.7 \mu \mathrm{m}$ channel (whose peak of sensitivity is in the upper troposphere), using the models' parameters, are evaluated against the Terra/MODIS satellite observations. The radiances generated are then converted to UTBT (or BT6.7: Brightness Temperature at $6.7 \mu \mathrm{m}$ wavelength) and UTRH. Clear sky and above low clouds satellite UTBT and the related UTRH are compared to the model simulations obtained through a forward radiative-transfer calculation procedure. The aim of this work is essentially to assess the degree of sensitivity of the NICAM and the NCEP/DOE UTBT and UTRH predictions under a variety of atmospheric conditions. To perform these simulations, the radiative transfer computations need thermal and humidity profiles outputs from the NICAM and the NCEP/DOE and MODIS geometrical parameters and spectral response. In brief, this work is organized as follows. The modeling environment (Section 1) then the major patterns of the distribution of the water vapour radiances observed (Section 2) are presented. In Section 3, comparisons between the observations and the model data are conducted. Section 4 consists of interpretations of the results (discrepancies) obtained in the previous chapter. The study ends with a general conclusion.

\section{Models and Satellite Environment}

The atmospheric models data tested in this study are the NICAM and NCEP/DOE models. The capacity of the atmospheric profiles generated by these models to reproduce satellite observation data is tested. The NICAM-generated data have a horizontal spatial resolution of $3.5 \times 3.5 \mathrm{~km}$. The NICAM model is a global cloud-resolving model used to simulate cumulus convection and allowing direct coupling of the atmospheric circulation and clouds [5]. It uses a fully compressible nonhydrostatic system and an icosahedral grid with spring dynamics smoothing. The model description can be found in Tomita et al. [6]. Other reports on this model include Satoh et al. $[7,8]$ where precipitation statistics between the model simulations and observations from the Tropical Rainfall Measuring Mission (TRMM) Precipitation Radar (PR) are discussed. Nasuno et al. [9] use moist physics global numerical experiments to study the multiscale convective organization in the Madden-Julian Oscillation (MJO) event that occurred during December 2006 and January 2007.

The NCEP/DOE model, with its reanalysis-2 data, are based on the widely used National Center for Environmental Prediction/ National Center for Atmospheric Research (NCEP/NCAR) reanalysis with improved parameterizations of the physical processes (convective and cloud parameterization and relative humidity-cloud relationship) compared to the initial version [10]. The model produces a 4-time daily data set with a spatial resolution of $2.5 \times 2.5$ degrees.

In this study, the NICAM and the NCEP/DOE data are selected at 00:00 UTC. The NICAM and NCEP/DOE predicted UTBT and UTRH are compared to observations from the $6.7 \mu \mathrm{m}$ channel of Terra/MODIS. This channel, with its peak of sensitivity in the upper troposphere, is very useful for the study of atmospheric processes. The Terra/ MODIS polar orbiting satellite $6.7 \mu \mathrm{m}$ channel has a spatial resolution of $0.01 \times 0.01$ degree at nadir. For a fair comparison between both the NICAM and NCEP/DOE models and the satellite observations, all the data were resized to a grid resolution of $0.5 \times 0.5$ pixel. The upper tropospheric radiances generated from the models' outputs are obtained through a forward computation process performed with the radiative transfer code RSTAR6b. This code is a general package for simulating radiation fields in the atmosphereland-ocean system at wavelengths between 0.17 and $1000 \mu \mathrm{m}$ $[11,12]$. The code assumes a plane parallel atmosphere divided into several homogeneous sublayers with underlying ground or ocean surface. To calculate the radiance field, the radiative transfer code needs pressure, temperature, and humidity atmospheric profiles from the models, as well as the satellite $6.7 \mu \mathrm{m}$ channel spectral response function and geometric parameters. 

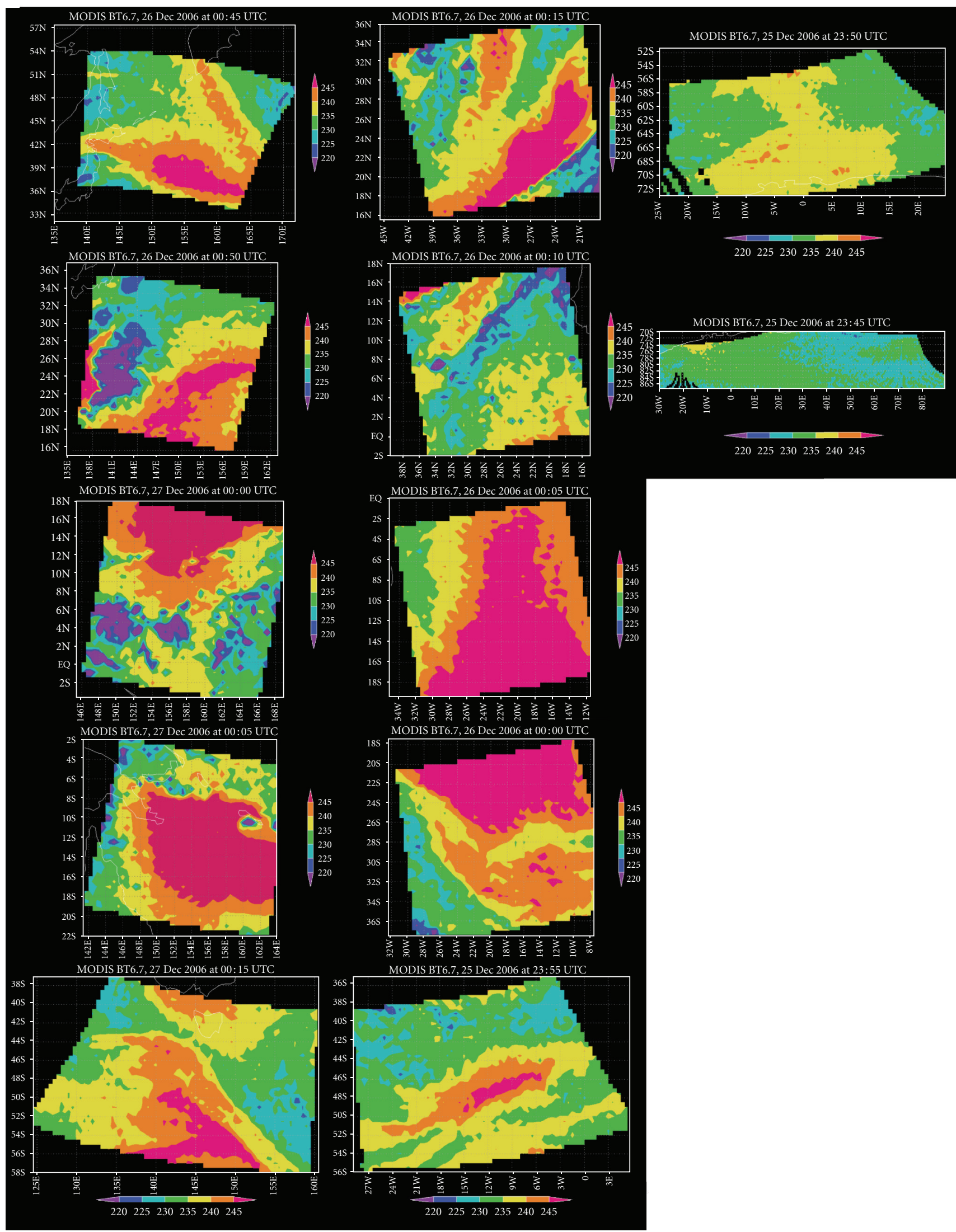

FIGURE 1: Brightness temperature at $6.7 \mu \mathrm{m}$ wavelength (BT6.7) in K, representing the upper tropospheric brightness temperature (UTBT) of MODIS scenes above the Pacific ocean (1st column) and the Atlantic ocean (2nd and 3rd Columns). 

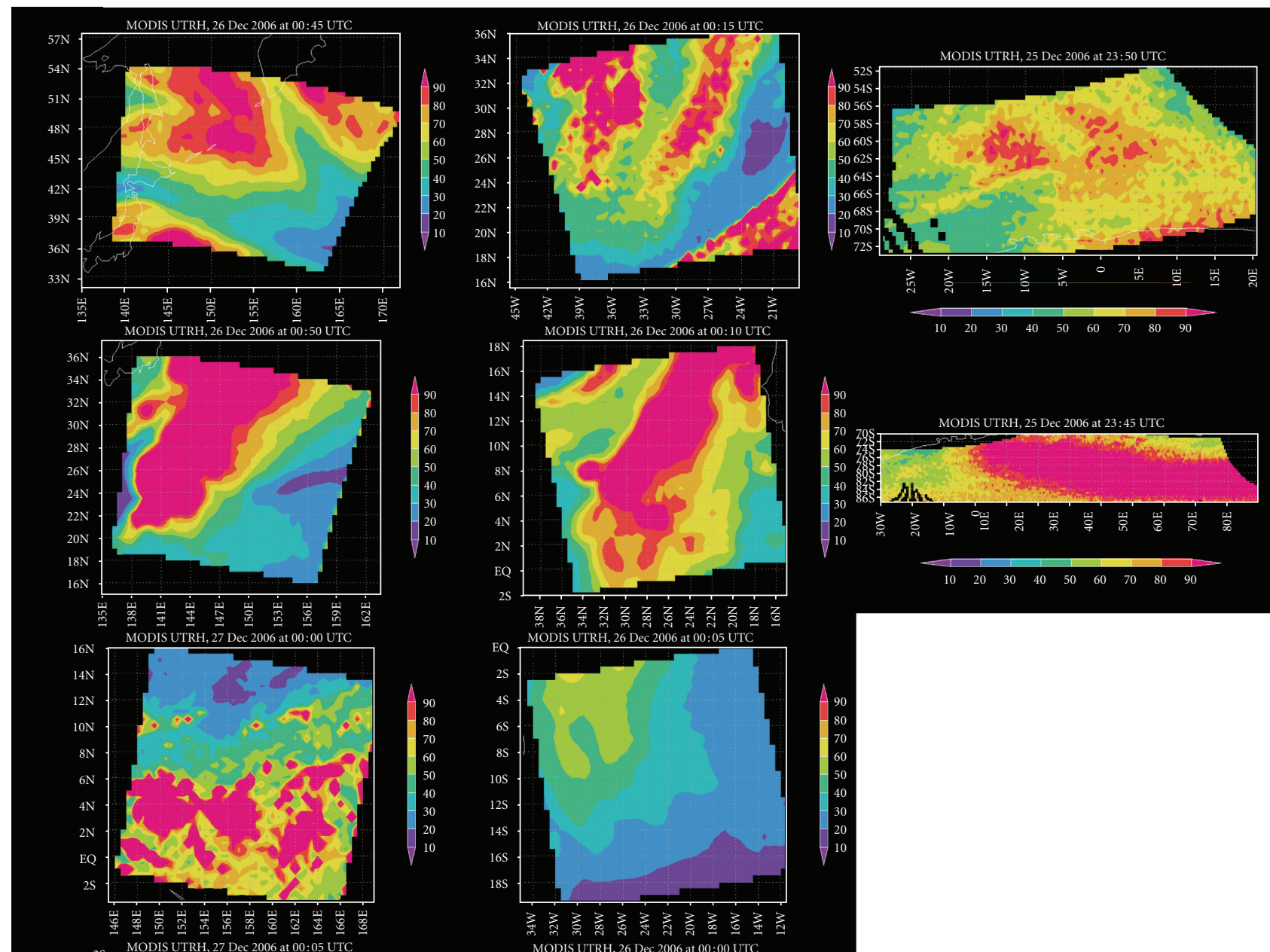

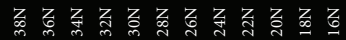
20
10
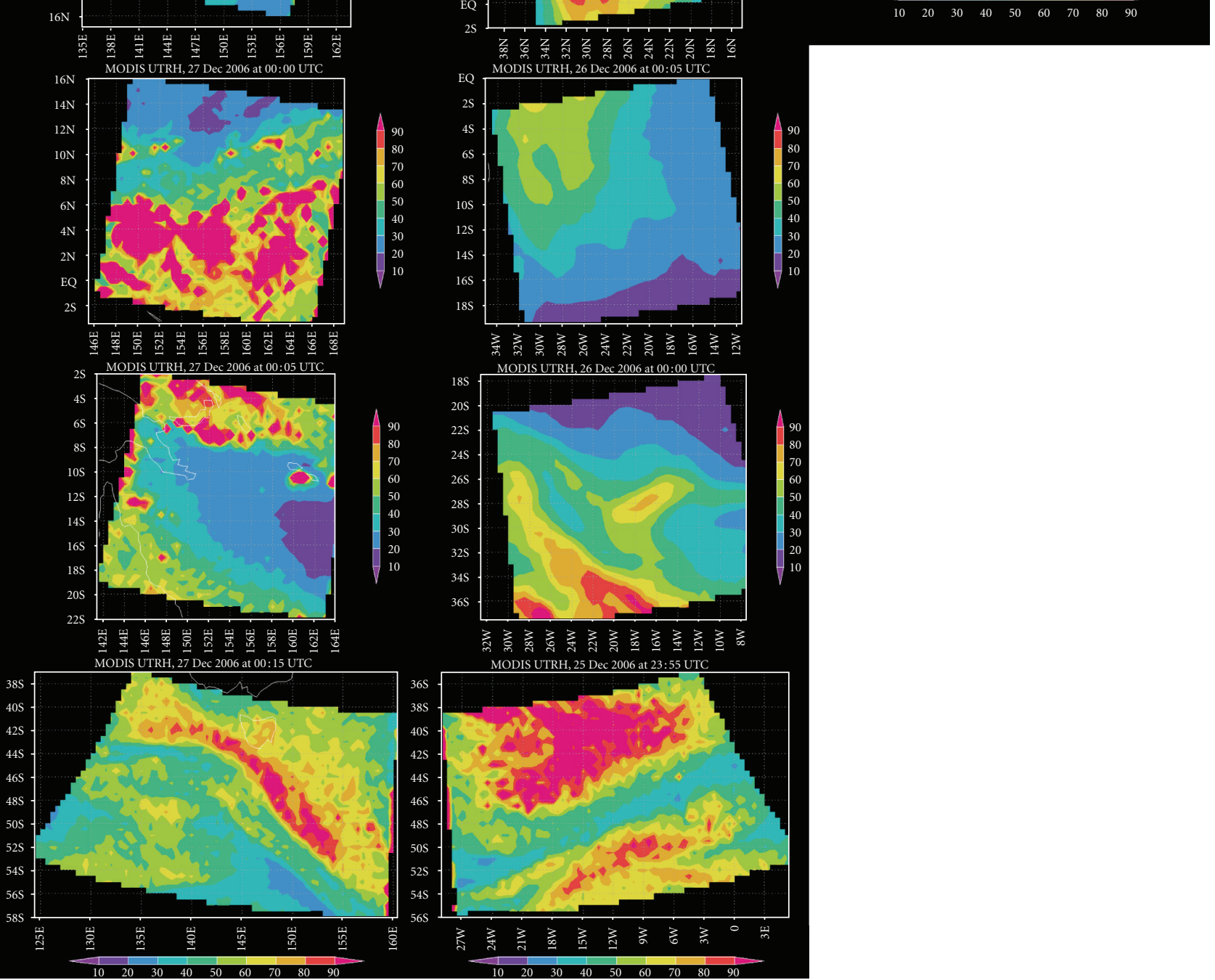

FIgURE 2: Same as Figure 1 but for the upper tropospheric relative humidity (UTRH). 


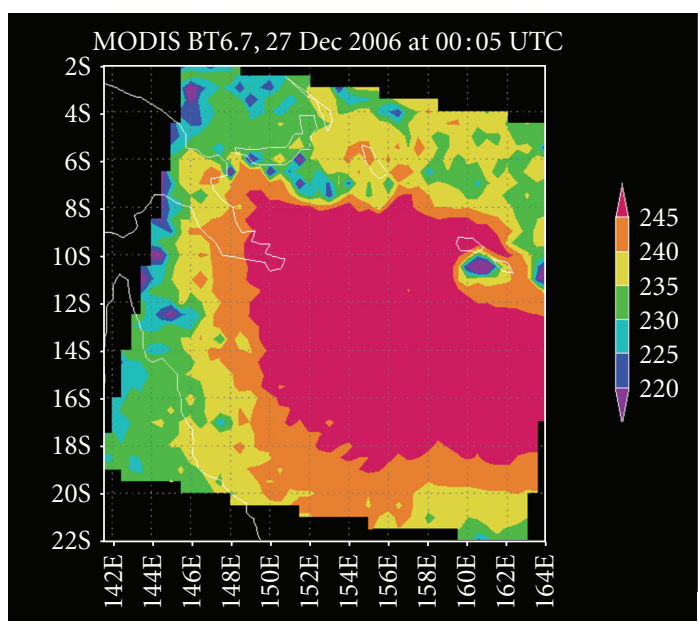

(a)

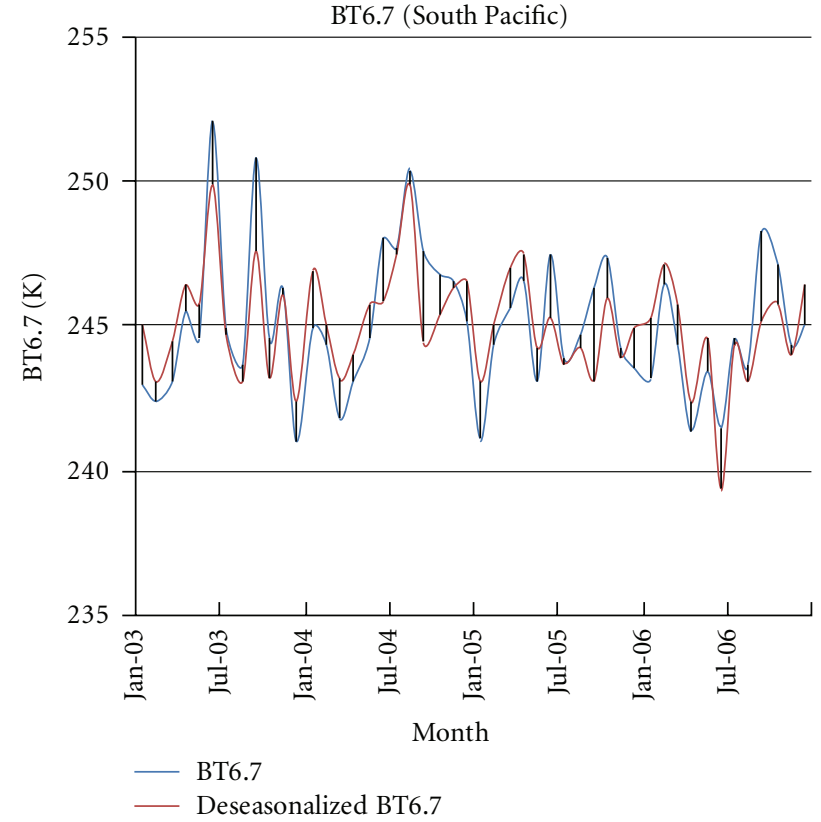

(b)

Figure 3: MODIS $6.7 \mu \mathrm{m}$ brightness temperature (BT6.7) distribution (a) and monthly variation (b) for the period from Jan 2003 to Dec 2006, showing the seasonality of this parameter in the South Pacific. The black vertical lines of the right figure represent the difference between the monthly variation and the deseasonalized variation.

The simulations were performed for the years 2003 to 2006 (NCEP/DOE) and 2006 (NICAM). The data sets presented in this study are simulations corresponding to a variety of Terra/MODIS scenes of December 25, 26, and 27, 2006, located all along the Atlantic and the Pacific oceans. The interpretations and conclusions obtained from these scenes are also valid for the scenes of the other years. Since even cirrus clouds are opaque at $6.7 \mu \mathrm{m}$, only clear sky pixels can be used for the analysis of upper tropospheric water vapor [3]. The atmospheres above low cloud areas can be used also, as the low clouds belong to the lower troposphere, that is, an area beyond the $6.7 \mu \mathrm{m}$ channel sensitivity and not interfering with this channel. This principle was applied to this study. The $6.7 \mu \mathrm{m}$ channel of the MODIS sensor is entirely sensitive in the atmospheric pressure range 500$200 \mathrm{mb}$. These levels will be used in the weighting, necessary for the estimation of the UTRH. The retrieval algorithm used for the derivation of the UTRH is based on the relation developed by Soden and Bretherton [13], between the infrared radiances and the upper tropospheric humidity:

$$
\ln \left(\frac{\mathrm{UTRH}}{\cos \theta}\right)=a+b \mathrm{BT}_{6.7}
$$

where UTRH is a weighted mean of the fractional relative humidity in the upper troposphere, $\theta$ is the satellite zenith angle, $\ln$ is the natural logarithm, $\mathrm{BT}_{6.7}$ is the radiance expressed as brightness temperature in the $6.7 \mu \mathrm{m}$ band, and $a$ and $b$ are regression coefficients determined from training data.

\section{Satellite Observations}

In this work, the Terra/MODIS water vapour channel $(6.7 \mu \mathrm{m})$ radiances are used to calculate the brightness temperature then the relative humidity of the upper troposphere through (1). The scenes selected are nighttime and daytime images. The geographical location of these scenes follows the descending and ascending paths of Terra/MODIS (along the Atlantic and Pacific oceans). Figures 1 and 2 present the distribution of the UTBT (BT6.7: brightness temperature at $6.7 \mu \mathrm{m}$ wavelength) and UTRH, respectively, for some of the scenes examined. These images show large portions of cold UTBT and high UTRH on Dec 26 (00:50, 00:45, 00:10, and 00:05 UTC) and Dec 27 (00:00 UTC). These cold areas correspond to high or middle cloud areas and are generally major centers of convection. Complex heat and moisture flow patterns are characterized by a large variability of UTBT with a warm pool spreading northward and southward from the Atlantic (25 Dec 23:45 23:55 UTC and 26 Dec 00:00 00:15 UTC) and westward from the Pacific (26 Dec at 00:45 and 00:50 UTC and 27 Dec at 00:00, 00:05, and 00:15 UTC). Cold temperatures of around $200 \mathrm{~K}$ representing regions of radiation sinks, and moisture subsidence areas with warm temperatures of more than $250 \mathrm{~K}$, can occur in a limited space (26 Dec at 00:50 UTC). This leads to the development of strong UTBT gradients. As expected, the polar areas show generally colder UTBT than tropical areas. Around convective areas, moist corners develop with UTRH of around 50\%. Around strong subsidence regions of the subtropics, UTRH may fall below $10 \%$. Substantial moisture gradients develop more frequently in tropical areas near 


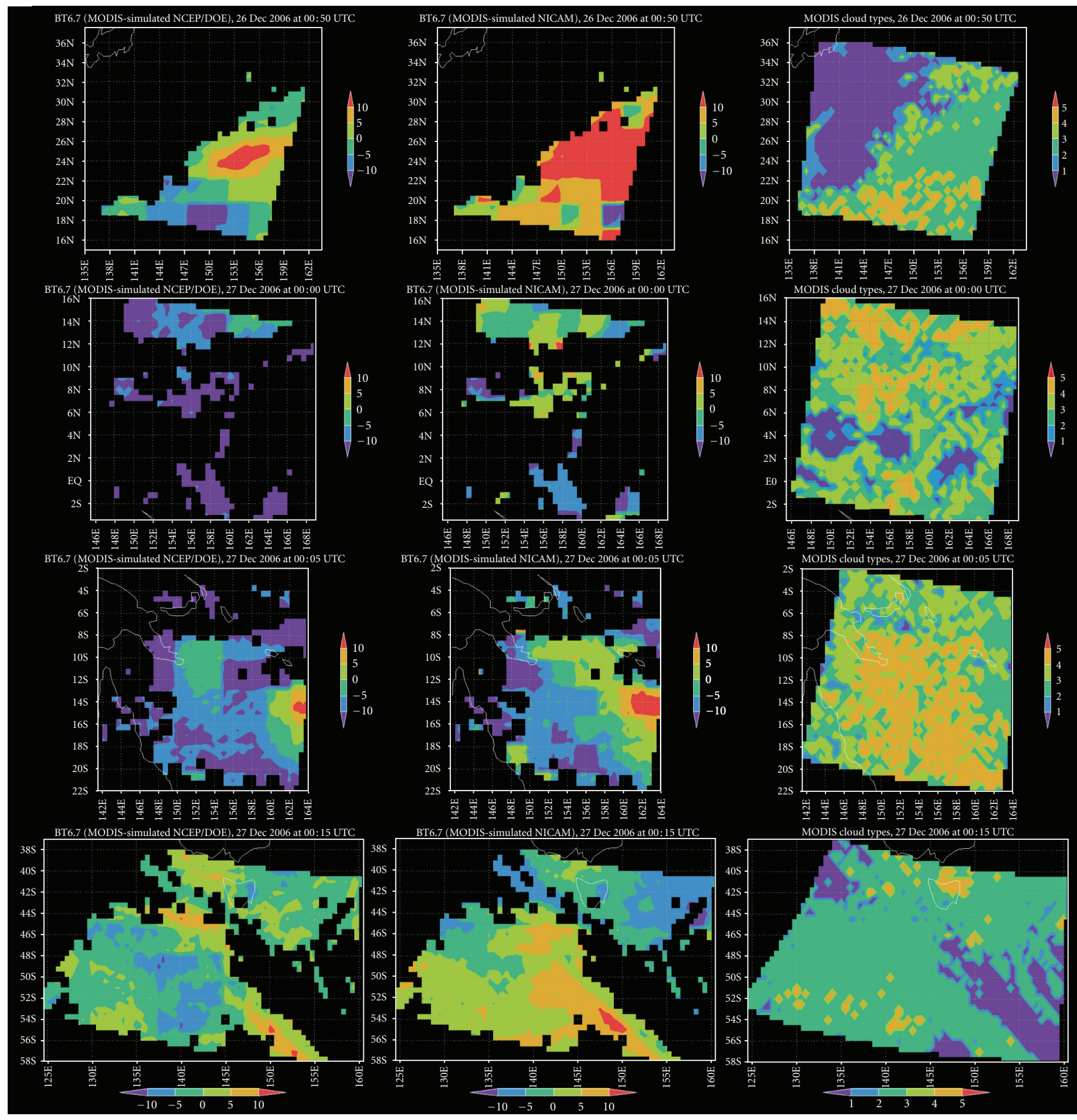

Figure 4: Differences between MODIS observed and NCEP/DOE simulated BT6.7 in K (1st column) then NICAM (2nd column), and the cloud types $(3$ rd column $)$ corresponding $(1=$ convective clouds, $2=$ middle clouds, $3=$ low clouds, $4=$ thin cirrus clouds and $5=$ clear sky).

the equator, with intensive upper flow UTBT taking place near highly moisturized areas. Low UTRH gradients occur mostly in the polar areas (25 Dec at 23:45 UTC) where UTBT spatial variability is relatively smooth. Warmer UTBTs near the equator indicate areas of relatively low water vapour amount in the upper troposphere. In such regions, the radiation to space is probably emitted from the lower troposphere. In the following section, a comparative analysis between the observation and model results is presented.

\section{Comparison between Observations and Model Results}

In this section we present the differences between the UTBT observed and modeled. These differences translate comparatively well to UTRH differences. Prior to these comparisons, it was necessary to examine Terra/MODIS seasonal variations data. This satellite's observations are known to be affected by seasonality issues. Figure 3 is an illustration of this 

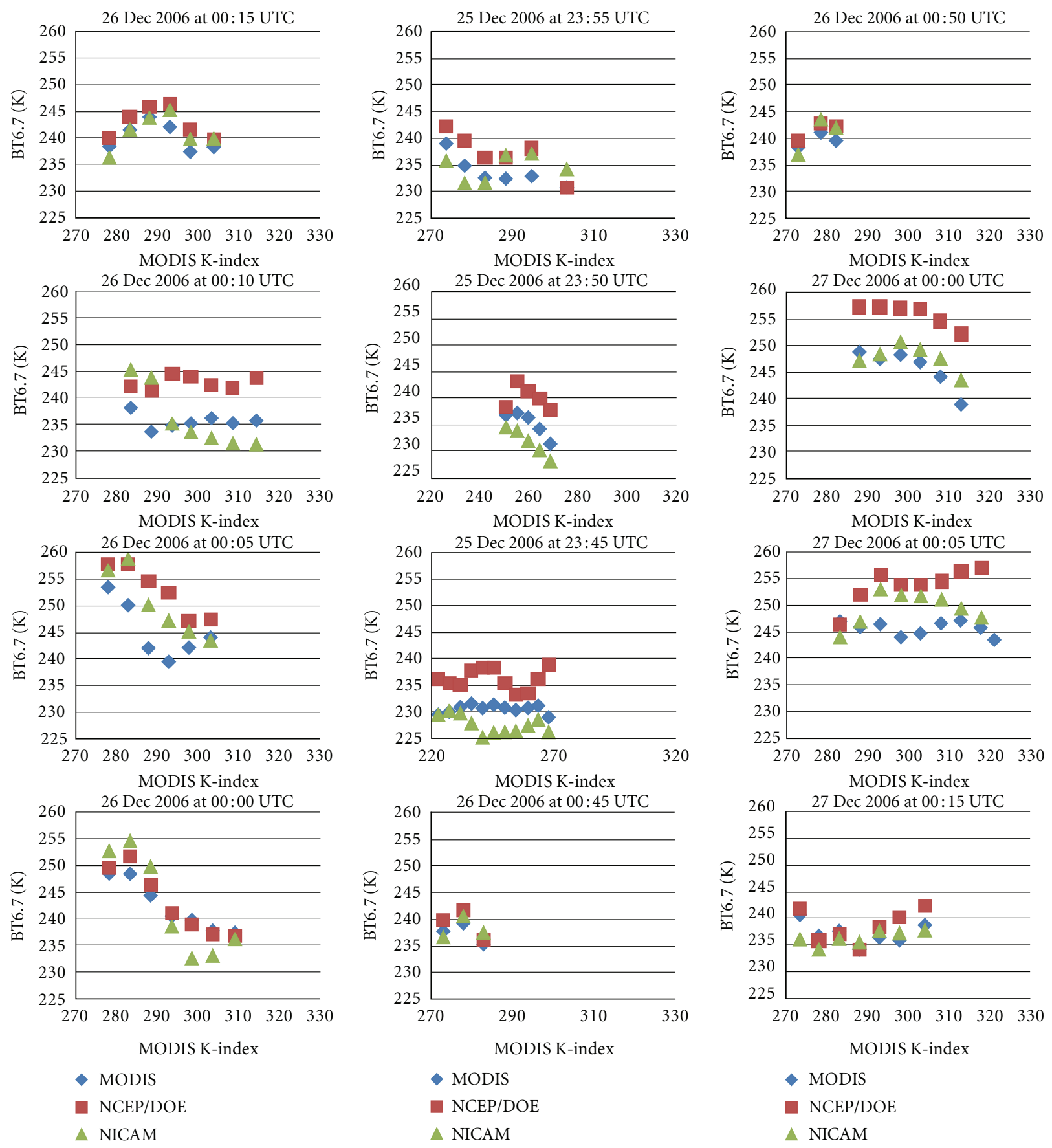

FIGURE 5: Variation of MODIS K-index with observed brightness temperature at $6.7 \mu \mathrm{m}$ wavelength (BT6.7) in K. Obs-NCEP: difference between observations and NCEP/DOE, Obs-NICAM: difference between observations and NICAM.

effect: for example, the deseasonalized UTBT observations of Dec 2006 are higher by around $1.5 \mathrm{~K}$ than the initial observations. These changes are taken into account in the comparisons between the satellite observations and the model simulations.

In this study, and for the data comparisons, positive differences mean warmer UTBT in the observations than model values. Differences between the observations and both models simulated water vapour generally show comparable patterns. Figure 4 presents the results of these differences at clear sky and above low cloud areas. This figure shows that these discrepancies are generally wider with the NICAM data compared to those of the NCEP/DOE. The latter's predictions are mostly negatively biased, that is, the model data are higher than the observed UTBT. These observations imply that the extent of the cold front propagation is generally limited in the NCEP/DOE representation of upper tropospheric radiances. The UTBT is, therefore, often overestimated. At very dry centers like the eastern central area of the scene of 26 Dec at 00:50 UTC (Figure 2) with UTBT 
TABLE 1: Correlation coefficient $(R)$ between observed and simulated UTBT (BT6.7) and UTRH during the year 2006. NCEP represents the NCEP/DOE data.

\begin{tabular}{|c|c|c|c|c|}
\hline Time & $R$ (UTBT) NCEP & $R$ (UTBT) NICAM & $R$ (UTRH) NCEP & $R(\mathrm{UTRH})$ NICAM \\
\hline 26 Dec at 00:15 & 0.775 & 0.714 & 0.752 & 0.729 \\
\hline 26 Dec at 00:10 & 0.166 & 0.383 & 0.207 & 0.497 \\
\hline 26 Dec at 00:05 & 0.451 & 0.682 & 0.205 & 0.530 \\
\hline 26 Dec at 00:00 & 0.857 & 0.717 & 0.800 & 0.637 \\
\hline 26 Dec at 23:55 & 0.703 & 0.426 & 0.632 & 0.316 \\
\hline 26 Dec at $23: 50$ & 0.720 & 0.625 & 0.588 & 0.248 \\
\hline 26 Dec at 23:45 & 0.455 & 0.260 & 0.661 & 0.658 \\
\hline 26 Dec at 00:45 & 0.702 & 0.606 & 0.820 & 0.711 \\
\hline 26 Dec at 00:50 & 0.432 & 0.129 & 0.592 & 0.306 \\
\hline 27 Dec at 00:00 & 0.837 & 0.626 & 0.733 & 0.500 \\
\hline 27 Dec at 00:05 & 0.536 & 0.497 & 0.482 & 0.306 \\
\hline 27 Dec at 00:15 & 0.748 & 0.365 & 0.660 & 0.302 \\
\hline
\end{tabular}

TABLE 2: RMSE (root mean square error) between the observation data and the NCEP/DOE, then the NICAM UTBT (TB6.7) and UTRH during the year 2006. NCEP represents the NCEP/DOE data.

\begin{tabular}{lll}
\hline Time & $\begin{array}{l}\text { RMSE NCEP } \\
\text { UTBT/UTRH }\end{array}$ & $\begin{array}{l}\text { RMSE NICAM } \\
\text { UTBT/UTRH }\end{array}$ \\
\hline 26 Dec at 00:15 & $5.333 / 14.613$ & $7.400 / 18.036$ \\
26 Dec at 00:10 & $8.384 / 25.382$ & $10.506 / 31.710$ \\
26 Dec at 00:05 & $10.253 / 18.892$ & $10.144 / 16.309$ \\
26 Dec at 00:00 & $4.915 / 10.735$ & $10.251 / 29.046$ \\
26 Dec at 23:55 & $4.468 / 14.428$ & $6.955 / 28.331$ \\
26 Dec at 23:50 & $5.544 / 23.295$ & $4.423 / 20.055$ \\
26 Dec at 23:45 & $6.543 / 25.952$ & $3.605 / 20.201$ \\
26 Dec at 00:45 & $4.011 / 13.06$ & $5.266 / 22.292$ \\
26 Dec at 00:50 & $5.918 / 13.562$ & $11.260 / 17.219$ \\
27 Dec at 00:00 & $12.150 / 29.729$ & $6.949 / 19.306$ \\
27 Dec at 00:05 & $11.363 / 23.139$ & $8.321 / 18.433$ \\
27 Dec at 00:15 & $3.581 / 12.246$ & $5.076 / 18.800$ \\
\hline
\end{tabular}

$>250 \mathrm{~K}$, models UTBTs are largely underestimated. And this is more conspicuous with the NICAM predictions than with the NCEP/DOE. When moist centers are close to dry areas, that is, there is a rapid change of temperatures (high gradients) (scene of $26 \mathrm{Dec}$ at 00:15 UTC), the dynamical force of the warm fronts seems to dominate that of the cold fronts in the models; the latter therefore tend to overestimate the UTBT compared to the observations. The models' bias is then predominantly negative. It is also noticeable that the models fail to capture large humidity minima of the water vapour field. Tables 1 and 2 present, respectively, the correlation coefficient between the observations and the models' results and the models' RMSE for both the UTBT and UTRH. For the NCEP/DOE, the highest UTBT RMSE values are found around the equator of both the Atlantic and the Pacific oceans (scenes of the 26th Dec 00:05 UTC and 00:10 UTC and the 27th Dec 00:00 UTC and 00:05 UTC).
These scenes generally show the lowest correlation coefficients. The situation is nearly similar with the NICAM model though the latter seems to behave better on scenes of the 27th Dec (reduced RMSE and better correlation coefficients). This improvement could be explained by the low start of the model initialization, that is, the change from a weak dynamic force reigning during the initial simulation day [3]. In the present study the initialization day of the NICAM simulations is the 26th Dec 2006. There may be a gradually stronger force on the next day, the 27th Dec 2006.

\section{Results' Interpretation and Discussion}

Reasons of the discrepancies noticed between the observations and the models' results are examined in this section. Among these, we will mainly examine the impacts on models results of the lower troposphere clear sky instability, the development of convective clouds, and the low cloud heat and moisture distributions (expressed through the cloud effective emissivity).

5.1. Atmospheric Instability (Dry Convection). Convection processes are at the origin of most of the air instability in the atmosphere. They can occur with cloud formation (moist convection) or without it (dry convection). In this part of the study, we examine the impact of the lower troposphere dry convection on model results. In a later section, the moist convection influence will be examined. The contribution of the thermodynamic instability from the lower troposphere heat and moisture to the water vapour and temperature distributions in the upper troposphere and the models' results can be assessed in various ways. One of them is the use of stability indicators. A commonly used indicator in this category is the K-index (KI). This index has demonstrated good capabilities to predict thunderstorms and convection areas for weather forecast. It is therefore a good measure of the precipitation and thunderstorm potential. The index uses the following parameters: the temperature difference, that is, the vertical temperature lapse rate between $850 \mathrm{hPa}$, or $T_{850 \mathrm{hPa}}$ 

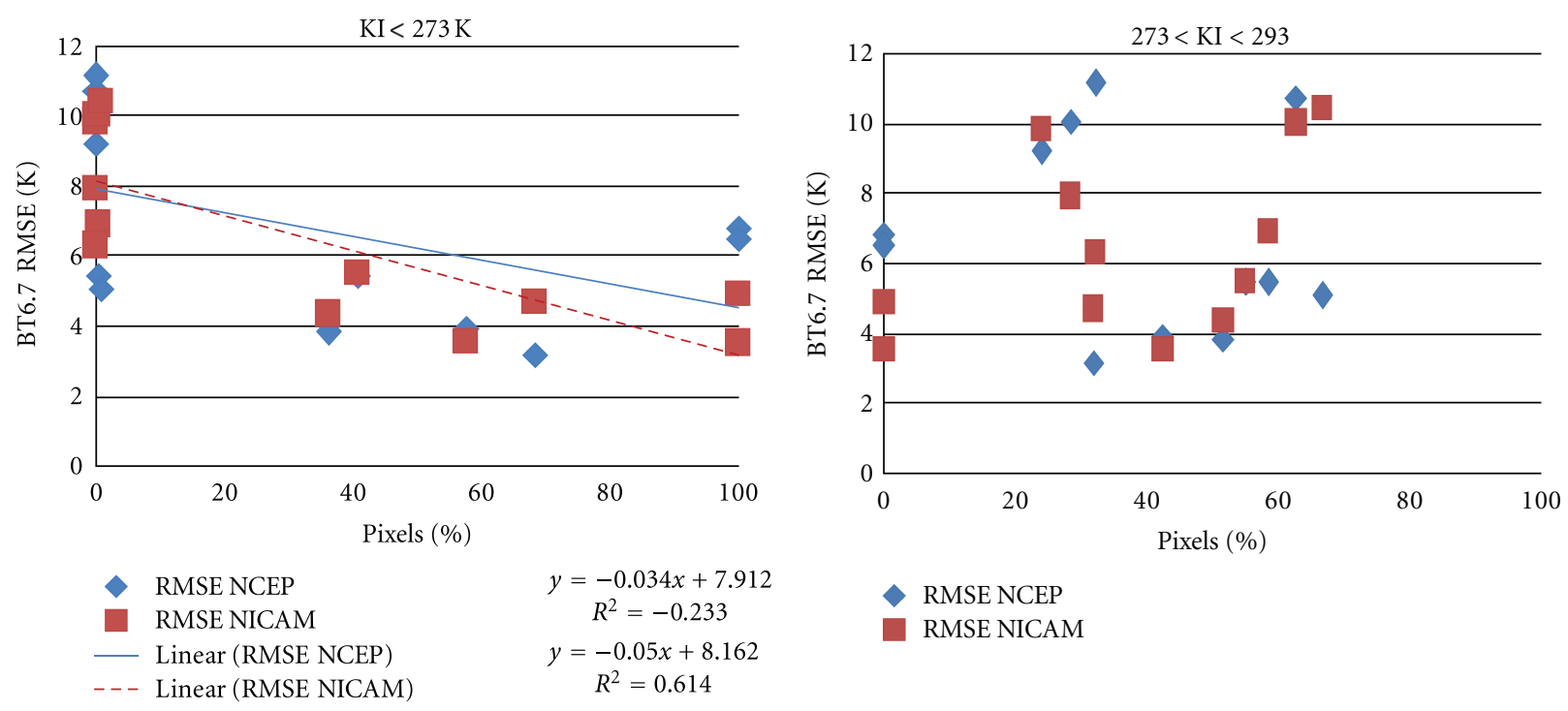

(a)

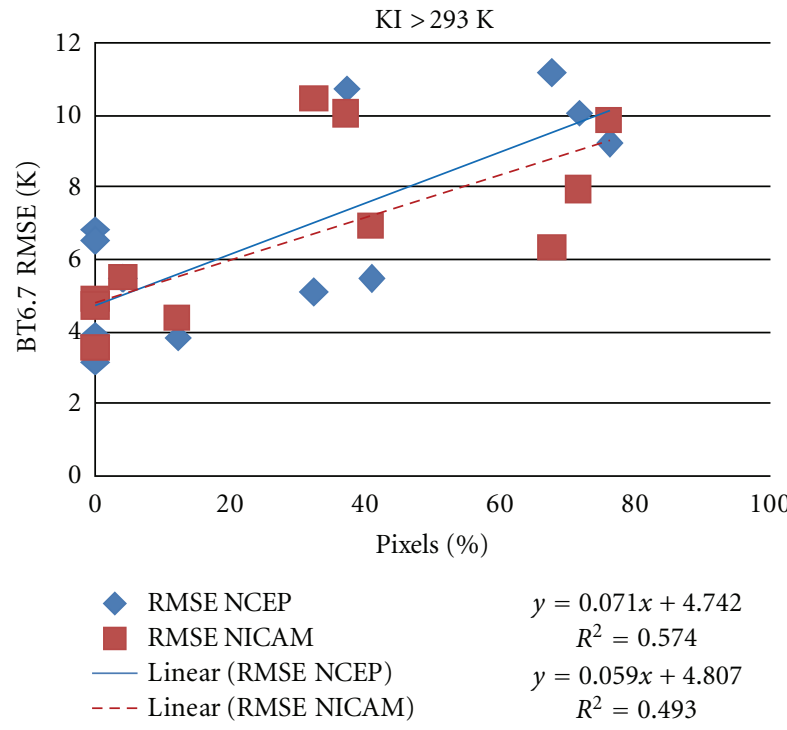

(c)

FIGURE 6: Relationship between clear sky coverage (in \%) in each K-index range, with the variation of the brightness temperature at $6.7 \mu \mathrm{m}$ wavelength (BT6.7) RMSE (between observations and models). The three classes $\mathrm{KI}<0,0<\mathrm{KI}<20$, and $\mathrm{KI}>20$ are, respectively, represented by $\mathrm{KI}<273 \mathrm{~K}, 273<\mathrm{KI}<293$, and KI $>293 \mathrm{~K}$.

and $500 \mathrm{hPa}$ or $T_{500 \mathrm{hPa}}$, the $850 \mathrm{hPa}$ dew point temperature or $T_{d 850 \mathrm{hPa}}$ (provides information on the moisture content of the lower atmosphere), the $700 \mathrm{hPa}$ dew point depression, that is, the difference between the temperature at $700 \mathrm{hPa}$ or $T_{700 \mathrm{hPa}}$ and the dew point temperature at $700 \mathrm{hPa}$ or $T_{d 700 \mathrm{hPa}}$ [14]. It is expressed as follows:

$$
\mathrm{KI}=\left(T_{850 \mathrm{hPa}}-T_{500 \mathrm{hPa}}\right)+T_{d 850 \mathrm{hPa}}-\left(T_{700 \mathrm{hPa}}-T_{d 700 \mathrm{hPa}}\right) .
$$

Compared to some other indicators, the K-index has the advantage of combining temperatures and humidity; it allows therefore a good distinction between dry and moist atmospheres. For KI less or equal to 0 (i.e., $273 \mathrm{~K}$ ), the atmosphere is generally stable. KI values between 0 and 20 (i.e., $273 \mathrm{~K}$ and $293 \mathrm{~K}$ ) constitute the transition or mix zone between stable and unstable atmospheres. For KI > 20 (i.e., $293 \mathrm{~K}$ ), the potential for convection and thunderstorms is high. Figure 5 presents the KI variation with the average UTBT (BT6.7) for all the scenes where KI covers the three stability ranges. The general pattern of the models' variation is comparable to that of the observations. However, some divergences (between the observations and the models) can be seen on $26 \mathrm{Dec}$ at 00:00, and 00:10 UTC, then $27 \mathrm{Dec}$ at 00:00 UTC for both models. The overall impact of the KI on the models is illustrated by Figure 6 . This figure presents 
the variation of the number of pixels (\% of data in clear sky areas) for the three major KI ranges identified earlier, with the UTBT RMSE between the observations and the models. A clear correlation is visible between these parameters for low $\mathrm{KI}(\mathrm{KI}<0)$ and high $\mathrm{KI}$ ranges $(\mathrm{KI}>20)$. The RMSE between both models' UTBT increases with the number of unstable areas' pixels and vice versa. The closeness of the determination coefficients between both models $\left(R^{2}=0.57\right.$ with NCEP/DOE and 0.49 with NICAM) and the number of pixels of $\mathrm{KI}<0$ means the stability of the lower troposphere has a comparable effect on both models' UTBT and UTRH predictions. However, the higher correlation with NICAM at $\mathrm{KI}>20$ may mean that the instability has a stronger effect on the latter model data than that of the NCEP/DOE. No visible correlation seems to exist in the transition zone of $\mathrm{KI}(0<\mathrm{KI}$ $<20$ ) as data are more randomly distributed.

5.2. Convective Clouds Effects (Moist Convection). Moist convection involves the formation of clouds. The presence of convective clouds is a sign of a strong atmospheric instability. Clouds of the study area were classified according to their brightness temperature in the thermal IR (infrared) window $(11 \mu \mathrm{m})$ and the water vapour IR $(6.7 \mu \mathrm{m})$ channels. For this purpose, the MODIS cloud mask products, that is, the 11 and $6.7 \mu \mathrm{m}$ radiances, are used. The simple classification scheme adopted is mostly based on the analysis of Roca et al. [15] and Chung et al. [16]. A cloud mask is added to these analyses to separate low clouds from clear sky areas. The classification steps are as follows.

(a) The pixel flagged as clear sky by the MODIS cloud mask is assigned the number (5).

(b) Then if the pixel is flagged as cloudy, it will belong to one of the following 4 classes:

(1) if BT11 (Brightness temperature at $11 \mu \mathrm{m}$ ) $<260 \mathrm{~K}$, the pixel is considered as part of convective clouds systems;

(2) if $270 \mathrm{~K}<\mathrm{BT} 11<260 \mathrm{~K}$, the pixel is part of middle clouds;

(3) if BT11 > $270 \mathrm{~K}$ and BT6.7 > $246 \mathrm{~K}$, the pixel is a low cloud;

(4) if BT11 > 270 K and BT6.7 < $246 \mathrm{~K}$, the pixel is a thin cirrus cloud.

An illustration of this distribution is given by the rightmost column of Figure 4. A large convective band covering almost half of the scene (West to East) of 26 Dec at 00:50 UTC shows the important propagation of these kinds of clouds. Conversely, very few convective cloud spots are seen on $27 \mathrm{Dec}$ at 00:00 and 00:05 UTC. Figure 7(a) shows the average observed UTBT with the amount of convective cloud cover. The UTBT appears to decrease with the increase of the convective cloud cover. The overall convective clouds effect is the moistening of the upper troposphere. The general depiction of the moisture variation by the models is quite comparable to that of the observations. The effect of this process on the model results can be determined by plotting the amount of convective clouds against the average UTBT difference (observation-model). Figure 7(b) shows this relationship. On one hand, a relatively good correlation is visible between the amount of convective clouds and the average difference (observation-NICAM), that is, there is a substantial increase of discrepancies with the amount of convective cloud cover. On the other hand, no clear correlation is noticeable with the NCEP/DOE results. In the following subsection, we will examine the effect of the low cloud effective emissivity on the heat distribution of the upper troposphere and the implications this may have on the model results.

5.3. Heat Distribution: Cloud Effective Emissivity. Cloud effective emissivity is the product of the cloud fraction and the cloud emissivity. The variation of effective emissivity through the vertical transmission of heat and humidity at the surface of low clouds can measurably influence changes of water vapour radiances of the upper troposphere. To analyze the impact of heat distribution above low clouds, the effective emissivity distribution of these clouds is examined. Before focusing on low clouds, we will first examine the effective emissivity of all clouds. Figure 8 shows the distribution patterns of all clouds areas' effective emissivity for similar scenes to those of Figure 4. Scenes of 27 Dec at 00:00 and 00:05 UTC show an important amount of low values of effective emissivity areas (i.e., high amounts of broken clouds) among clusters of full clouds while the scenes of $26 \mathrm{Dec}$ at 00:50 and $27 \mathrm{Dec}$ at 00:15 UTC have fewer pixels of low effective emissivity for all the cloud types. For the latter two scenes, the low effective emissivity pixels are essentially aligned along the southwest-northeast and southeastnorthwest directions, respectively. A quick comparison of these scenes with the corresponding UTBT differences on Figure 4 (at the top and bottom rows, respectively) shows that strong discrepancies are along the major low emissivity paths (belonging to middle or high clouds). For low clouds only and clear sky areas, a quantitative evaluation of the differences is presented ahead, for all the scenes (Figure 9). On this figure are plotted the variations of the UTBT average difference (observation-models) with the effective emissivity (in 20\% ranges). Clear sky areas are shown as $0 \%$ effective emissivity. The general patterns of these graphs show that the least differences occur at no emissivity (i.e., clear sky areas) and high emissivity areas (continuous clouds). The highest discrepancies are seen near intermediate effective emissivity values, around 40 to $60 \%$. A succinct interpretation of these observations is provided by Figure 10. This figure shows the variation of the low clouds' amount within the sum (clear sky and low clouds) with the UTBT RMSE for the three major classes of cloud effective emissivity $(E)$ ranges selected (effective emissivity less than $40 \%$, between 40 and $80 \%$, and above $80 \%)$. There is an increase of the error (RMSE) with the increase of the amount of low clouds in the low and average effective emissivity ranges ( $E<40 \%$ and $40<E<80 \%$ ) while the error decreases with the increase of the amount of low clouds for the high effective emissivity range. This implies that both models' depiction of the upper troposphere water 


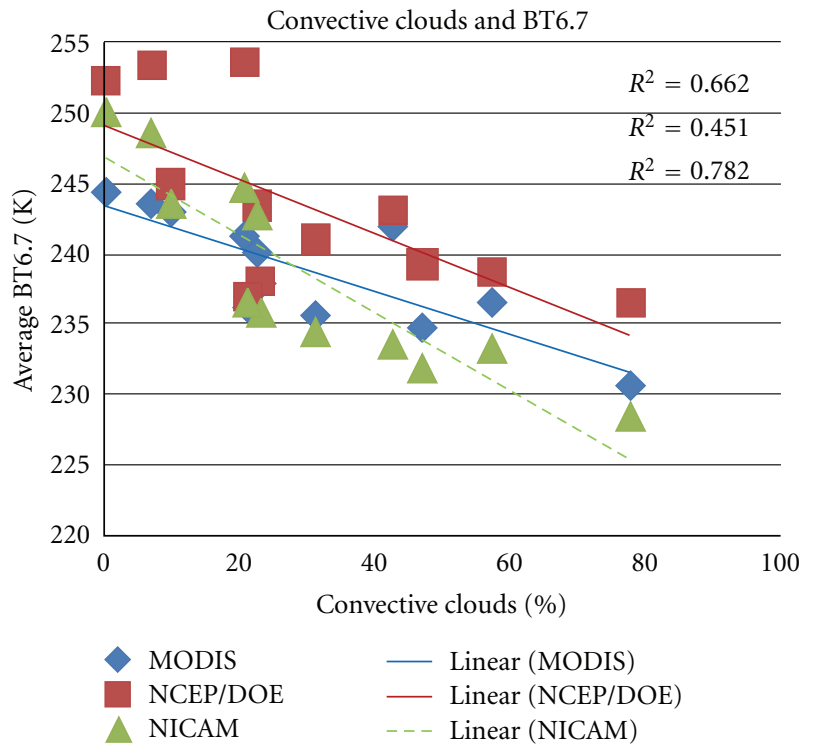

(a)

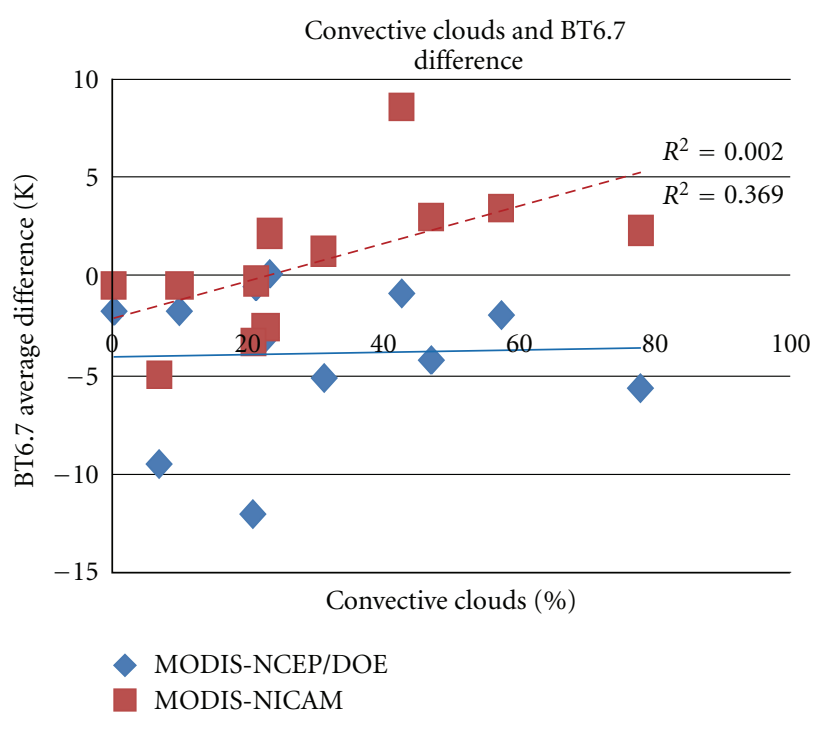

(b)

FIGURE 7: Variation of the convective cloud cover (\%) for each MODIS scene with the average observed brightness temperature at $6.7 \mu \mathrm{m}$ wavelength (BT6.7) (a), then the BT6.7 difference (MODIS-NCEP/DOE and MODIS-NICAM) (b). The determination coefficients on the right of (a) are, respectively, for MODIS (upper), NCEP/DOE (middle), and NICAM (lower); for (b), they are for MODIS-NCEP/DOE (upper) and MODIS-NICAM (lower).

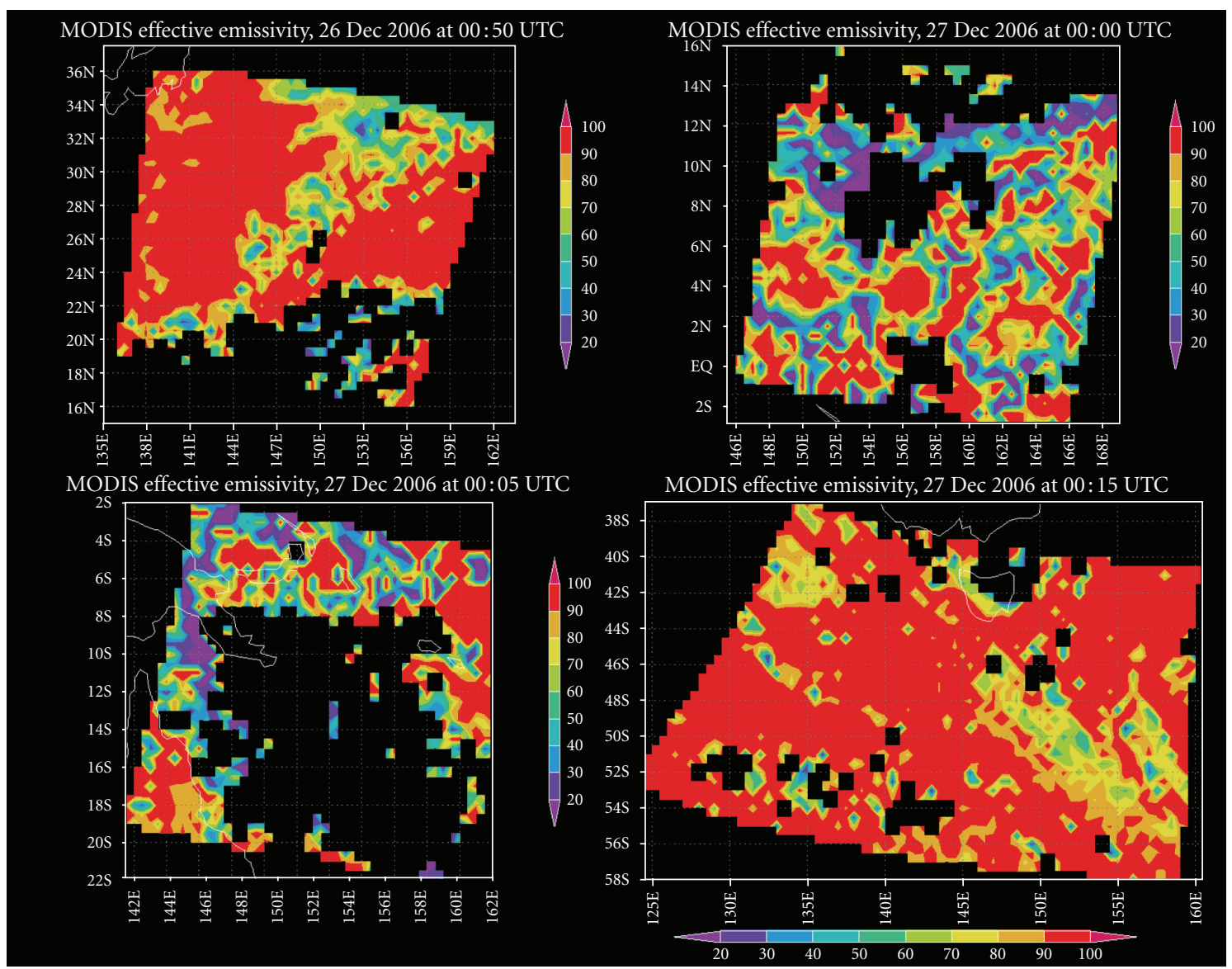

FIgURE 8: Distribution of the effective emissivity corresponding to similar scenes as those of Figure 4. 

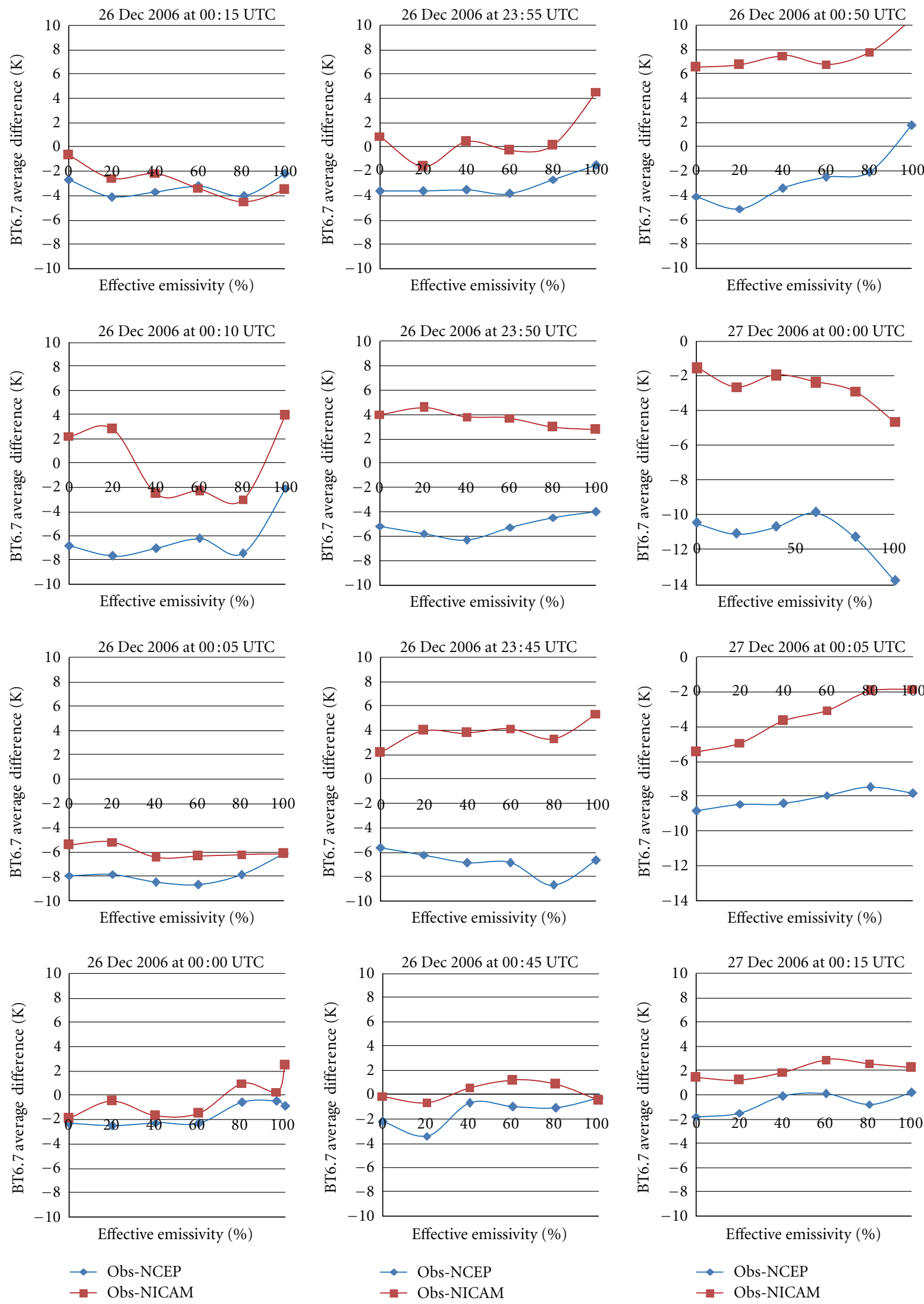

FIGURE 9: Effective emissivity against average brightness temperature difference at $6.7 \mu \mathrm{m}$ (BT 6.7) wavelength. 

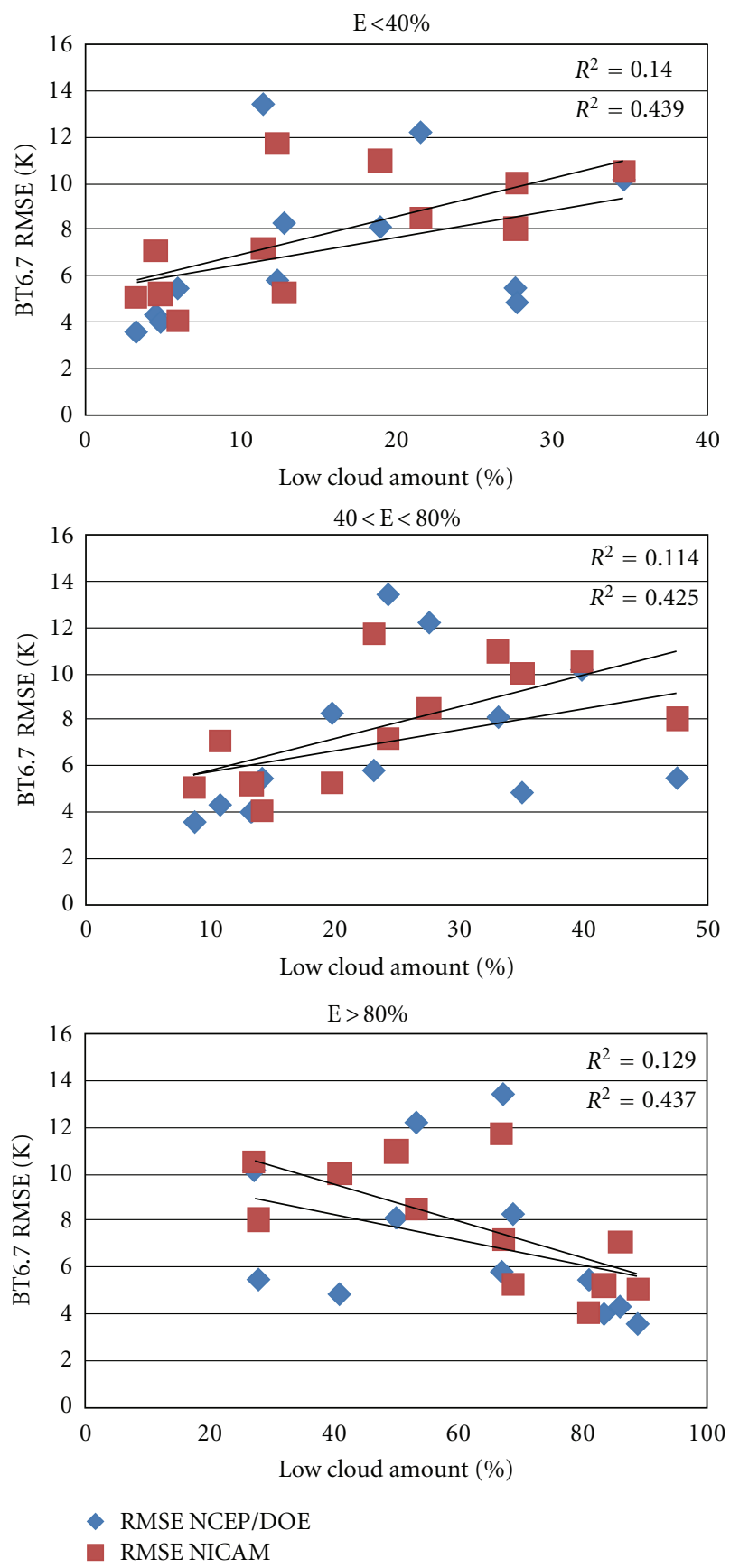

FIGURE 10: Variation of the amount of low cloud (\% of low clouds' pixels to the sum of clear sky and low clouds) with the brightness temperature at $6.7 \mu \mathrm{m}$ (BT6.7) wavelength RMSE for various cloud effective emissivity $(E)$ ranges. The determination coefficients on the right in each frame are, respectively, for the relation between the low cloud amount and both the RMSE NCEP/DOE (upper) and RMSE NICAM (lower).

vapour above broken clouds is poor. Fewer errors are seen when clouds with a high effective emissivity are abundant, that is, when there is a wider spatial continuity. The determination coefficient is stronger with NICAM data than with NCEP/DOE predictions. Large inconsistencies are noticed between the observation and the model simulations for scenes having a high frequency of low clouds with low effective emissivity (Figure 8, scene of Dec 27 at 00:00 UTC). The NCEP/DOE UTBT RMSE was as high as $12 \mathrm{~K}$ for that scene
(Table 2). When only few low clouds with low effective emissivity are present (Table 2 and Figure 8, scene of 27 Dec 2006 at 00:15 UTC), the RMSE is low and the correlation coefficient for both models is high. In general and as shown by Figure 10, the effect of low cloud brokenness on the upper tropospheric humidity seems stronger (increase of UTBT discrepancies) with the NICAM than the NCEP/DOE models.

Besides the reasons evoked so far to explain the discrepancies between the satellite observations and the model, there 
is the degree of uncertainty related to the MODIS cloud mask. The errors in the cloud detection of the satellite sensor may lead to the lowering of the accuracy of the models' data. Generally, ambiguities in the cloud detection of the satellite occur at the edges of the thick clouds and with some thin high clouds. Though the MODIS cloud mask algorithm uses various cloud detection tests to determine the confidence level of clear sky observations, some clouds may still be difficult to identify. A MODIS cloud detection algorithm and a ground-based combination Micropulse Lidar/Millimeter Cloud Radar (MPL/MMCR) study, reported by Ackerman et al. [17], shows that there is an agreement on the existence of clear or probably clear sky, $86 \%$ of the time, and, $92 \%$ of the time, a cloud is present. A visual examination of the images used in this study shows that cloud contamination may not appear to have significantly affected the results of the present study (comparisons between satellite observations and models' simulations).

\section{Conclusion}

In order to evaluate the performance of large and mesoscale atmospheric circulation models (NCEP/DOE and NICAM), respectively, and their capacity to reproduce satellite observations, water vapour radiances of Terra/MODIS $6.7 \mu \mathrm{m}$ channel (whose peak of sensitivity is in the upper troposphere) are simulated. The products derived from these radiances (UTBT and UTRH) are compared with MODIS observations. The tests beds for the models' evaluation are the atmosphere above the north and south of the Pacific and the Atlantic oceans. Analyses of the models' simulations show that they reproduce well enough the satellite observation patterns. The discrepancies between these models and the observations appear higher with the NICAM than with the NCEP/DOE (the latter shows generally lower RMSE values). The correlation coefficient between the observations and the models is generally better with the NCEP/DOE than the NICAM. However, for most of the scenes, the UTBT simulated by the NCEP/DOE is overestimated. This is particularly the case near the equator where the highest UTBT/UTRH RMSEs among the NCEP/DOE predictions are found. At very dry and warm pools, the NICAM results are often underestimated. Reasons of the discrepancies between the models and observations were examined and discussed in terms of the vertical heat and moisture movements in clear sky areas (dry convection) between the lower and the upper troposphere and above low cloud areas (cloud effective emissivity) and the convective clouds' (moist convection) influence on heat distribution. The contribution of the lower troposphere instability to the upper tropospheric moisture and implications for the models' results are analyzed through a thunderstorm and moisture predictor (the K-stability index). A positive correlation between the instability and the RMSE (observation versus models) is noticed with both models. The study of the effect of the convective clouds' development on the models results shows that, as the area covered by these clouds increases, both the humidity in the upper troposphere and the UTBT RMSE between the observations and the NICAM model tend to increase also. The NCEP/DOE model is not as much affected as the NICAM model, by this phenomenon. Analyses of the impact of the heat distribution above low clouds areas are also conducted based on the cloud effective emissivity distribution. Areas with low values of cloud effective emissivity show the strongest discrepancies with the observations for both models. This effect seems to be much more noticeable with the NICAM than with the NCEP/DOE results. The most reliable results are obtained either in clear sky or continuous cloud areas. In order to improve the model data, corrections should include further adjustments of the cloud-resolving parameters, that is, the predictive capacity of the models in the integration of clouds and cloud microphysical properties.

\section{Acknowledgment}

The authors would like to thank Pr. M. Satoh of the University of Tokyo for providing the Japan Aerospace Exploration Agency (JAXA), with the NICAM model outputs, used for this study.

\section{References}

[1] B. Soden, S. Tjemkes, J. Schmetz et al., "An intercomparison of radiation codes for retrieving upper-tropospheric humidity in the $6.3-\mu \mathrm{m}$ band: a report from the first GVaP workshop," Bulletin of the American Meteorological Society, vol. 81, no. 4, pp. 797-808, 2000.

[2] A. Gettelman, W. D. Collins, E. J. Fetzer et al., "Climatology of upper-tropospheric relative humidity from the Atmosphere Infrared Sounder and implication for climate," Journal of Climate, vol. 19, no. 23, pp. 6104-6121, 2006.

[3] D. A. Spangenberg, G. G. Mace, T. P. Ackerman, N. L. Seaman, and B. J. Soden, "Evaluation of model-simulated upper troposphere humidity using $6.7 \mu \mathrm{m}$ satellite observations," Journal of Geophysical Research D, vol. 102, no. 22, pp. 25737-25749, 1997.

[4] X. Wu and X. Li, "A review of cloud-resolving model studies of convective processes," Advances in Atmospheric Sciences, vol. 25, no. 2, pp. 202-212, 2008.

[5] H. Miura, M. Satoh, T. Nasuno, A. T. Noda, and K. Oouchi, "A Madden-Julian oscillation event realistically simulated by a global cloud-resolving model," Science, vol. 318, no. 5857, pp. 1763-1765, 2007.

[6] H. Tomita, H. Miura, S. Iga, T. Nasuno, and M. Satoh, "A global cloud-resolving simulation: preliminary results from an aqua planet experiment," Geophysical Research Letters, vol. 32, no. 8, pp. 1-4, 2005.

[7] M. Satoh, T. Matsuno, H. Tomita, H. Miura, T. Nasuno, and S. Iga, "Nonhydrostatic icosahedral atmospheric model (NICAM) for global cloud resolving simulations," Journal of Computational Physics, vol. 227, no. 7, pp. 3486-3514, 2008.

[8] M. Satoh, T. Nasuno, H. Miura, H. Tomita, S. Iga, and Y. Takayabu, "Precipitation statistics comparison between global cloud resolving simulation with NICAM and TRMM PR data," in High Resolution Numerical Modelling of the Atmosphere and Ocean, K. Hamilton and W. Ohfuchi, Eds., pp. 99-112, Springer, 2008.

[9] T. Nasuno, H. Miura, M. Satoh, A. T. Noda, and K. Oouchi, "Multi-scale organization of convection in a global numerical 
simulation of the December 2006 MJO event using explicit moist processes," Journal of the Meteorological Society of Japan, vol. 87, no. 2, pp. 335-345, 2009.

[10] M. Kanamitsu, W. Ebisuzaki, J. Woollen et al., "NCEP-DOE AMIP-II reanalysis (R-2)," Bulletin of the American Meteorological Society, vol. 83, no. 11, pp. 1631-1643, 2002.

[11] T. Nakajima and M. Tanaka, "Matrix formulations for the transfer of solar radiation in a plane-parallel scattering atmosphere," Journal of Quantitative Spectroscopy and Radiative Transfer, vol. 35, no. 1, pp. 13-21, 1986.

[12] T. Nakajima, M. Tsukamoto, Y. Tsushima, A. Numaguti, and T. Kimura, "Modeling of the radiative process in an atmospheric general circulation model," Applied Optics, vol. 39, no. 27, pp. 4869-4878, 2000.

[13] B. J. Soden and F. P. Bretherton, "Upper tropospheric relative humidity from the GOES $6.7 \mu \mathrm{m}$ channel: method and climatology for July 1987," Journal of Geophysical Research, vol. 98, no. 9, pp. 16669-16688, 1993.

[14] J. J. George, Weather Forecasting for Aeronautics, Academic Press, 1960.

[15] R. Roca, M. Viollier, L. Picon, and M. Desbois, "A multisatellite analysis of deep convection and its moist environment over the Indian Ocean during the winter monsoon," Journal of Geophysical Research D, vol. 107, no. 19, article 8012, 2002.

[16] E. S. Chung, B. J. Sohn, and V. Ramanathan, "Moistening processes in the upper troposphere by deep convection: a case study over the tropical Indian Ocean," Journal of the Meteorological Society of Japan, vol. 82, no. 3, pp. 959-965, 2004.

[17] S. Ackerman, K. Strabala, P. Menzel et al., Discriminating clear-sky from cloud with MODIS algorithm. Theoretical basis document (MOD35), 2006, http://modis-atmos.gsfc.nasa/ .gov_docs/atbd_mod06.pdf. 

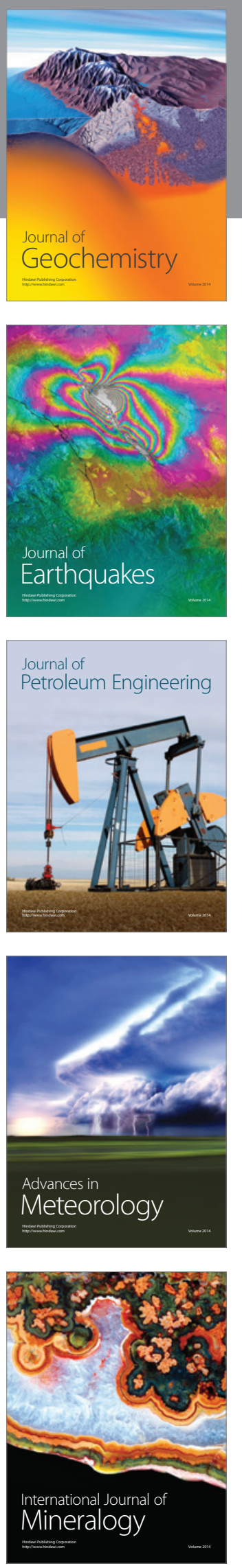
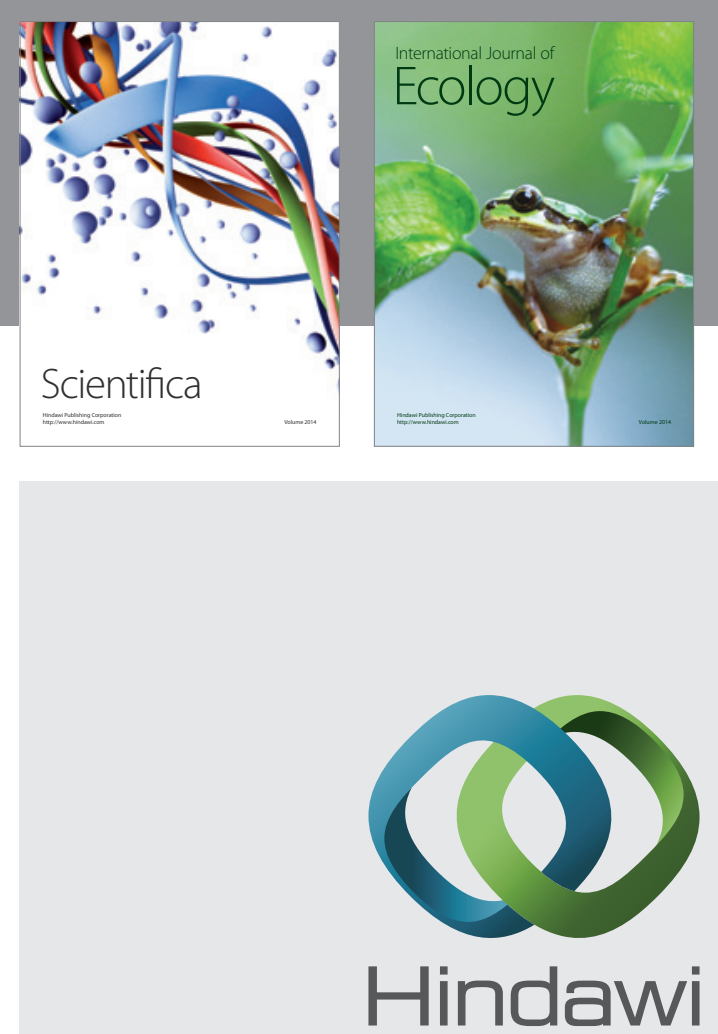

Submit your manuscripts at http://www.hindawi.com
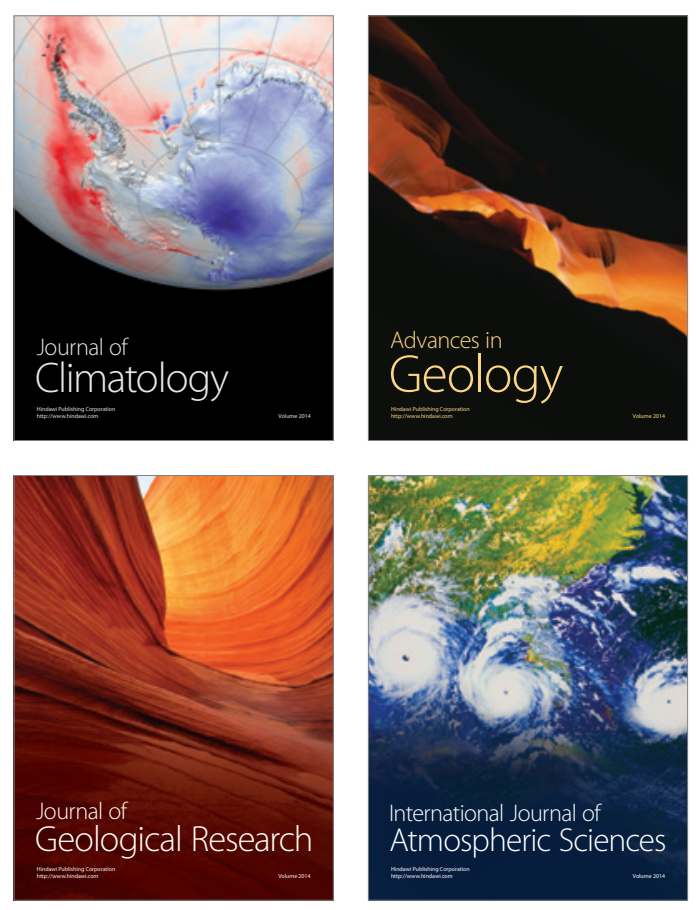
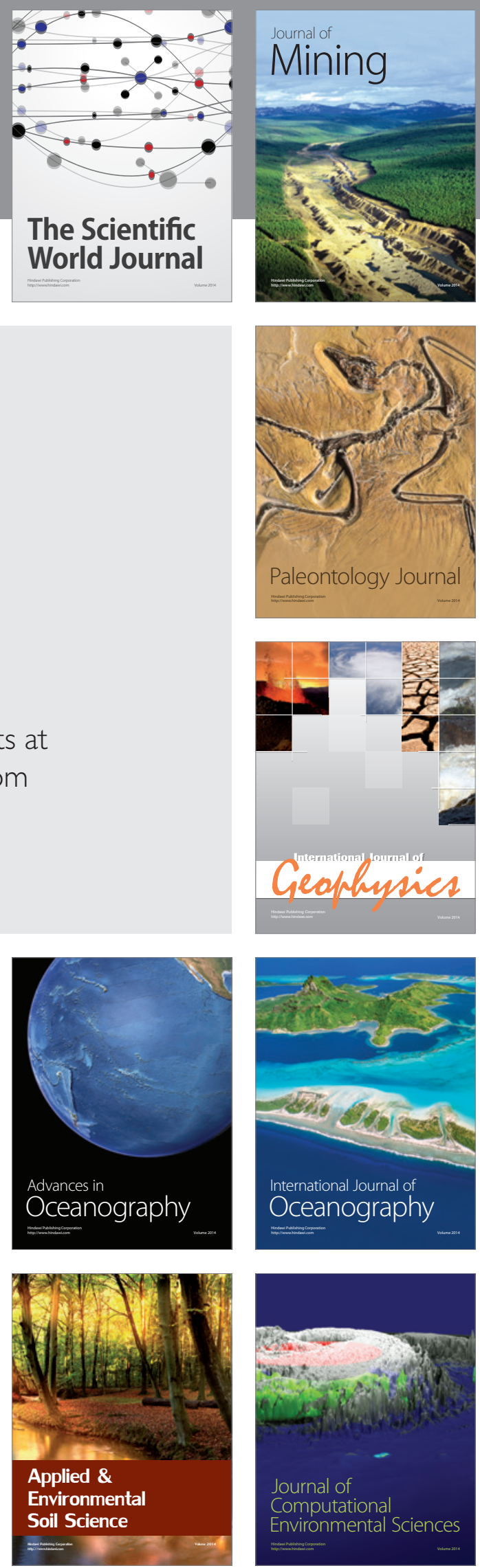